\title{
Perbaikan Kualitas Buah Jambu Biji (Psidium guajava L.) Kultivar Getas Merah melalui Aplikasi GA3, sebagai Upaya Meningkatkan Daya Saing Buah Lokal
}

\author{
NI NYOMAN ARI MAYADEWI ${ }^{*)}$ DAN I MADE SUKEWIJAYA \\ Program Studi Agroekoteknologi Fakultas Pertanian Universitas Udayana \\ J1. PB. Sudirman, Denpasar 80231 Bali \\ *)E-mail: arimayadewi@yahoo.com
}

\begin{abstract}
Quality Improvement of Guava Fruit (Psidium guajava L.) "Getas Merah" Cultivar Through GA3 Application, as an Effort to Increase Local Fruit Competitiveness. This study aimed to improve the quality of fruit of Getas Merah guava, which reduces the content of fruit seeds by giving gibberellic acids (GA3). This research was conducted in Banjar Lawak, Bilok Sidan Village, Petang District, Badung Regency from July to November 2017. The area of guava plant used by farmers with rental system. Samples taken in the field and then analyzed at the Laboratory of Agronomy and Horticulture Faculty of Agriculture Udayana University. Analysis of chemical content of fruits carried out in Food Analysis Laboratory Faculty of Agricultural Technology Udayana University. This experiment was a one-factor experiment with GA3 concentration of six levels i.e. $\mathrm{G} 0=0$ ppm, G1 $=50 \mathrm{ppm}, \mathrm{G} 2=100 \mathrm{ppm}, \mathrm{G} 3=150 \mathrm{ppm}, \mathrm{G} 4=200 \mathrm{ppm}$ and G5 $=250 \mathrm{ppm}$. Each level of treatments was repeated 5 times. The results showed that there was a decrease of seed content in fruit of 9.24\% (GA3 of $50 \mathrm{ppm}$ ), 13.99\% (GA3 of $100 \mathrm{ppm}$ ), 46.33\% (GA3 of $150 \mathrm{ppm}$ ), $48.92 \%$ (GA3 of $200 \mathrm{ppm}$ ), and $65.01 \%$ (GA3 of $250 \mathrm{ppm}$ ) when compared to controls. In this study the treatment of several levels of concentration can reduce the number of seeds, but can not make fruit without seeds.
\end{abstract}

Keywords: GA3, guava, fruit quality

\section{PENDAHULUAN}

Jambu biji (Psidium guajava, L) merupakan salah satu jenis buah-buahan yang mempunyai potensi besar untuk dikembangkan dalam rangka pemenuhan gizi masyarakat, karena mengandung vitamin $\mathrm{C}$ yang tinggi (87 mg dalam $100 \mathrm{~g}$ jambu biji), dua kali lebih banyak bila dibandingkan dengan kandungan vitamin $\mathrm{C}$ jeruk manis (Parimin, 2007). Jambu biji juga mengandung antoksidan yang tinggi (Yan, et $a l .$, 2006), yang berfungsi untuk membantu 


\section{NI NYOMAN ARI MAYADEWI DAN I MADE SUKEWIJAYA. Perbaikan Kualitas Buah Jambu...}

melindungi tubuh dari radikal bebas. Jambu biji dapat dikonsumsi dalam keadaan segar sebagai buah meja, ataupun diolah menjadi sirop, sari buah, selai, jeli, ataupun dodol. Jambu biji mempunyai rasa dan aroma yang khas disebabkan oleh senyawa eugenol serta mengandung senyawa kimia quercentin dari golongan flavonoid yang efektif menaikkan jumlah trombosit dalam darah. Kandungan tanin dalam daun jambu biji mujarab untuk mengatasi diare, gastroenteritis, dan keluhankeluhan lain yang berhubungan dengan pencernaan (Soedarya, 2010).

Kultivar jambu biji yang disukai oleh masyarakat adalah jambu dengan ukuran buah besar, rasa manis, warna merah, tekstur renyah, dan kandungan biji sedikit. Kenyataannya dari beberapa jenis jambu biji yang dijumpai di lapangan, sebagian besar memiliki biji banyak, kecuali jambu biji sukun dan kristal. Untuk jambu biji dengan daging buah berwarna putih, jambu biji kristal menduduki urutan teratas disukai oleh masyarakat. Jambu biji dengan daging buah berwarna merah kebanyakan masih mengandung jumlah biji yang banyak. Jambu biji Getas Merah, merupakan salah satu jambu biji dengan warna daging buah berwarna merah, memenuhi beberapa persyaratan antara lain ukuran buah besar, rasa manis, tapi masih mengandung biji yang banyak. Jambu biji getas merah banyak digunakan untuk jus atau dimakan segar sebagai buah meja.

$\mathrm{GA}_{3}$ adalah zat pengatur tumbuh yang sangat berperan pada tanaman buah-buahan untuk meningkatkan pertumbuhan dan hasil baik kuntitas maupun kualitas. Aplikasi $\mathrm{GA}_{3}$ (asam giberelin) sebelum bunga mekar pada tanaman anggur Bali dapat meningkatkan rasa manis dan mengurangi jumlah biji secara signifikan, namun mengurangi ukuran buah (Astawa et al., 2015). Pemberian $\mathrm{GA}_{3}$ terbukti dapat meningkatkan mutu buah pada tanaman peach (Dagara et al., 2012), stroberi (Azadi et al., 2013), dan Kurma (Awad and Al-Qurashi, 2012), tapi belum ditemukan pada jambu biji Getas Merah. Penyemprotan $\mathrm{GA}_{3} 20$ ppm tiga kali telah mencukupi untuk menghasilkan buah tanpa biji pada tomat genotipe 'Gamato 3'. Penyemprotan $\mathrm{GA}_{3} 30$ ppm tiga kali meningkatan kadar padatan total terlarut (PTT) namun cenderung menurunan ukuran dan kekerasan buah (Adnyesuari et al., 2015). Penelitian ini bertujuan untuk memperbaiki kualitas jambu biji Getas Merah, khususnya mengurangi kandungan biji dalam buah dengan pemberian gibberellic acids $\left(\mathrm{GA}_{3}\right)$. 


\section{BAHAN DAN METODE}

Penelitian ini dilaksanakan di Desa Plaga Kecamatan Petang, Kabupaten Badung dari bulan Juli sampai Nopember 2017. Areal tanaman jambu biji yang digunakan milik petani setempat dengan populasi tanaman yang memadai untuk digunakan sebagai tempat percobaan. Sampel yang diambil di lapangan kemudian di analisis di Laboratorium Agronomi dan Hortikultura Fakultas Pertanian Universitas Udayana. Analisis kandungan kimia buah dilaksanakan di Laboratorium Analisis Pangan Fakultas Teknologi Pertanian Universitas Udayana.

Tanaman jambu biji kultivar Getas Merah terpilih diberi perlakuan pemeliharaan sesuai standar GAP (good agriculture practice), tanaman diberi pupuk baik pupuk NPK maupun pupuk kandang untuk pertumbuhan vegetatif tanaman. Penelitian ini hanya akan dilakukan pada satu kali masa berbuah dan akan mengikuti teknik budidaya yang dilakukan petani, namun perbedaannya adalah adanya aplikasi $\mathrm{GA}_{3}$ dengan jalan penyemprotan pada bunga jambu biji yang dihasilkan oleh tunas produktif pada stadia bunga mekar.
Bahan dan alat yang digunakan dalam penelitian ini adalah $\mathrm{GA}_{3}$, air, kertas label, benang, hand sprayer, plastic, gunting dahan, timbangan, dan meteran. Percobaan ini merupakan percobaan satu faktor yaitu konsentrasi $\mathrm{GA}_{3}$. Konsentrasi $\mathrm{GA}_{3}$ yang diaplikasi meliputi 6 level yaitu $\mathrm{G} 0=0$ ppm; $\mathrm{G} 1=50$ ppm; $\mathrm{G} 2=100$ ppm; G3 = 150 ppm; G4 = 200 ppm; dan G5 = 250 ppm. Masing masing perlakuan diulang sebanyak 5 kali.

Panen buah jambu biji dilakukan pada saat buah sudah memenuhi kriteria panen, yaitu tangkai buah tampak kekuningan, berwarna hijau pekat menjadi berwarna muda keputih-putihan dan halus.

\section{HASIL DAN PEMBAHASAN}

Variabel yang diamati pada percobaan ini adalah rata-rata jumlah biji, kandungan vitamin $\mathrm{C}$ dan kadar gula total. Hasil pengamatan terhadap kandungan biji di dalam buah setelah perlakuan dapat dilihat pada Tabel 1, dan kandungan vitamin $\mathrm{C}$ dan gula total disajikan pada Tabel 2. 
NI NYOMAN ARI MAYADEWI DAN I MADE SUKEWIJAYA. Perbaikan Kualitas Buah Jambu...

Tabel 1. Rata-rata Jumlah Biji Per Buah dan Penurunan Jumlah Biji dibandingkan Kontrol Jambu Biji Getas Merah pada Berbagai Konsentrasi GA 3

\begin{tabular}{lcc}
\hline $\begin{array}{c}\text { Perlakuan } \\
(\mathrm{ppm})\end{array}$ & Rata-rata jumlah biji & $\begin{array}{c}\text { Penurunan jumlah biji } \\
\text { dibandingkan kontrol (\%) }\end{array}$ \\
\hline 0 & $333,20 \mathrm{a}$ & - \\
50 & $302,40 \mathrm{ab}$ & 9,24 \\
100 & $286,60 \mathrm{c}$ & 13,99 \\
150 & $178,80 \mathrm{c}$ & 46,33 \\
200 & $170,20 \mathrm{c}$ & 48,92 \\
250 & $116,60 \mathrm{~d}$ & 65,01 \\
\hline
\end{tabular}

Keterangan: Nilai yang diikuti huruf sama pada kolom yang sama menunjukkan tidak berbeda nyata berdasarkan uji Duncan $(\mathrm{P}<0,05)$.

Data dari Tabel 1 menunjukkan terjadi penurunan jumlah biji dengan pemberian konsentrasi $\mathrm{GA}_{3}$. Semakin tinggi konsentrasi $\mathrm{GA}_{3}$ yang diaplikasikan, semakin sedikit kandungan biji dalam buah. Rata-rata penurunan jumlah biji yang tertinggi diperoleh pada perlakuan 250 ppm. Hasil tertinggi tersebut berbeda sangat nyata dengan perlakuan lainnya yang lebih rendah. Namun demikian, hasil ini belum dapat dikatakan sebagai hasil yang maksimal dengan masih banyaknya biji yang terbentuk pada buah. Target untuk menjadikan jambu biji yang tanpa biji (seedless) masih memungkinkan dengan cara melakukan percobaan lanjutan dengan konsentrasi yang lebih tinggi. Konsentrasi $\mathrm{GA}_{3}$ yang lebih tinggi tersebut dimungkinkan karena masih ada kecenderungan penurunan jumlah biji dari perlakuan konsentrasi terendah sampai dengan yang tertinggi yang dicoba pada penelitian ini.

Hasil penelitian menunjukkan juga terjadi penurunan kandungan biji dalam buah masing-masing 9,24\% (pemberian $\mathrm{GA}_{3} 50$ ppm), 13,99\% (pemberian $\mathrm{GA}_{3} 100$ ppm), 46,33\% (pemberian $\mathrm{GA}_{3} 150$ ppm), 48,92\% (pemberian $\mathrm{GA}_{3} 200$ ppm), dan 65,01\% (pemberian $\mathrm{GA}_{3} 250$ ppm) bila dibandingkan dengan kontrol. Pada penelitian ini perlakuan beberapa tingkat konsentrasi mampu menurunkan jumlah biji, tetapi belum bisa membuat buah tanpa biji.

Secara alami, polen mengandung auksin dan giberelin endogen (Sari, 2010). Pada buah berbiji normal, auksin dan giberelin yang dibawa bersama tumbuhnya pollen tube dilepas setelah tabung polen mencapai ovul sehingga akan terbentuk biji dan merangsang pembesaran ovarium. $\mathrm{GA}_{3}$ eksogen diduga dapat menggantikan peran 
giberelin yang terdapat dalam biji pada buah. Giberelin $\left(\mathrm{GA}_{3}\right)$ dapat mengurangi jumlah biji apabila diterapkan pada tanaman berbunga.

Perlakuan $\mathrm{GA}_{3}$ mengakibatkan tidak terbentuknya biji karena gangguan pertumbuhan tabung sari sebelum pembuahan. Hormon giberelin akan mencegah sampainya buluh serbuk sari ke celah mikrifil pada ovarium dengan merusak dan menghambat perkembangan buluh serbuk sari. Hal ini mengakibatkan sel sperma tidak dapat bertemu dengan sel telur sehingga zigot tidak terbentuk. Jika zigot tidak terbentuk maka perkembangan biji terhenti dan tidak terbentuk biji, sehingg pemberian giberelin mampu menginduksi tebentuknya buah secara partenokarpi (Pardal, 2001).
Masih adanya biji juga diduga karena adanya serbuk sari dari tanaman lain dan konsentrasi larutan $\mathrm{GA}_{3}$ yang diberikan belum optimal. Pada satu kali penyemprotan, ovul masih banyak yang terbuahi oleh gamet karena sekali penyemprotan $\mathrm{GA}_{3}$ belum mampu meningkatkan secara langsung kandungan giberelin endogen pada ovari sebelum pembuahan sehingga beberapa ovul masih terbuahi. Sastry \& Muir (1963) menyatakan bahwa konsentrasi giberelin pada ovarium baru akan meningkat setelah 28 jam semenjak aplikasi dilakukan (aplikasi dilakukan satu kali sebelum bunga mekar pada kuncup bunga tomat).

Tabel 2. Kandungan Vitamin C dan Total Gula Jambu Biji Getas Merah pada Berbagai Konsentrasi $\mathrm{GA}_{3}$

\begin{tabular}{ccccc}
\hline $\begin{array}{c}\text { Perlakuan } \\
(\mathrm{ppm})\end{array}$ & $\begin{array}{c}\text { Vitamin C } \\
(\mathrm{mg} / 100 \mathrm{~g})\end{array}$ & $\begin{array}{c}\text { Total gula } \\
(\%)\end{array}$ & $\begin{array}{c}\text { Prosentase } \\
\text { peningkatan kadar } \\
\text { Vit C } \\
\text { dibandingkan } \\
\text { kontrol }\end{array}$ & $\begin{array}{c}\text { Prosentase } \\
\text { peningkatan kadar } \\
\text { total gula } \\
\text { dibandingkan } \\
\text { kontrol }\end{array}$ \\
\hline 0 & 322,69 & 2,58 & - & - \\
50 & 339,62 & 3,06 & 5,25 & 18,60 \\
100 & 353,66 & 2,99 & 9,60 & 15,89 \\
150 & 362,77 & 3,29 & 12,42 & 27,52 \\
200 & 393,25 & 3,81 & 21,87 & 47,67 \\
250 & 362,91 & 3,26 & 12,46 & 26,36 \\
\hline
\end{tabular}


NI NYOMAN ARI MAYADEWI DAN I MADE SUKEWIJAYA. Perbaikan Kualitas Buah Jambu...

Kandungan vitamin $\mathrm{C}$ dan total gula jambu biji Getas Merah menunjukkan bahwa semakin tinggi konsentrasi GA3 yang diberikan maka semakin tinggi kandungan vitamin $\mathrm{C}$ dan total gulanya. Peningkatan kandungan vitamin $\mathrm{C}$ dengan konsentrasi 200 ppm menunjukkan hasil yang tertinggi, dan bila dibandingkan dengan control peningkatan kandungan vitamin C-nya meningkat 21,87\%. Angka ini lebih tinggi dibandingkan dengan konsentrasi lainnya. Hasil penelitian Handarin dan Haryati (2013) menunjukkan pemberian GA3 pada konsentrasi hingga 750 ppm nyata meningkatkan kadar vitamin $\mathrm{C}$ buah tomat dibandingkan perlakuan dengan konsentrasi yang lebih rendah sampai 300 ppm. Hasil penelitian Handarin dan Haryati (2013) mengindikasikan ada sedikit perbedaan dengan hasil penelitian aplikasi GA3 pada jambu biji ini karena dengan konsentrasi yang lebih rendah (200 ppm) dapat meningkatkan kandungan vitamin $\mathrm{C}$ sampai $21,87 \%$, namun pada konsentrasi yang lebih tinggi mengindikasikan penurunan.

Sejalan dengan kandungan vitamin $\mathrm{C}$, kandungan gula total pada perlakuan GA3 200 ppm juga dapat meningkatkan kandungan gula total sampai $3,81 \%$. Bila dibandingkan dengan control, perlakuan tersebut dapat meningkatkan kandungan gula total sampai 47,67\%. Hasil penelitian Adnyesuari et al. (2015) menunjukkan bahwa penyemprotan GA3 yang jauh lebih rendah dari aplikasi pada jambu biji 30 ppm tiga kali semprot dapat meningkatan kadar padatan total terlarut (PTT) namun cenderung menurunan ukuran dan buah kekerasan pada tanaman tomat tiga genotipe tomat yang diuji yaitu 'Gamato 3', 'Kaliurang 206', dan 'Intan'.

\section{SIMPULAN}

Berdasarkan hasil penelitian dapat disimpulkan bahwa aplikasi $\mathrm{GA}_{3}$ saat bunga mekar pada tanaman jambu biji mampu menurunkan kandungan biji dalam buah. $\mathrm{GA}_{3}$ dengan konsentrasi 250 ppm dapat menurunkan kandungan biji sebesar 65,01\% bila dibandingkan dengan kontrol, tetapi belum bisa membuat buah jambu biji tanpa biji.

Dari hasil penelitian dapat disarankan bahwa perlu dilakukan penelitian lanjutan dengan menambah konsentrasi $\mathrm{GA}_{3}$ dan menambah frekuensi aplikasi karena belum diperoleh konsentrasi yang optimum. Perlu dilakukan penelitian dengan mencari sumbersumber $\mathrm{GA}_{3}$ alami yang harganya lebih murah, karena $\mathrm{GA}_{3}$ sintetik harganya mahal. 


\section{UCAPAN TERIMA KASIH}

Penulis menyampaikan terima kasih atas bantuan pendanaan yang diberikan oleh Universitas Udayana melalui DIPA PNBP Universitas Udayana Sesuai dengan Surat Perjanjian Penugasan Penelitian Nomor: 1726/UN14.2.6.II/LT/2017, tanggal $14 \mathrm{Juli}$ 2017.

\section{DAFTAR PUSTAKA}

Astawa, I N.G., R. Dwiyani, N.N.A. Mayadewi, I M. Sukewijaya, N.L.M. Pradnyawati. 2015. Perbaikan Kualitas Buah Anggur Bali (Vitis vinifera var. Alphonso lavallee) melalui Aplikasi GA3 Sebelum Bunga Mekar. Agrotrop 5 (1): 37-41

Adnyesuari, A.A., R.H. Murti, \& S. Mitrowihardjo. 2015. Induksi partenokarpi pada tiga genotipe tomat dengan GA3. Ilmu Pertanian 18 (1): 56-62.

Awad, M.A. \& A.D. Al-Qurashi. 2012. Gibberellic acid spray and bunch bagging increasebunch weight and improve fruit quality of 'Barhee' date palm under hot arid conditions. Scientia Horticulturae 138: 96-100

Azadi, Z., M. Jafarpour, A.R. Golparvar, \& A. Mohammadkhani. 2013. Effect of GA3 Application on Fruit Yield, Flowering and Vegetative CHARACTERISTICS ON Early Yield of Strawberry cv. Gaviola. Int. J. Agric. and Crop Sci. 5 (15): 17161718.

Bourke, B.O.D. 1976. Psidium Guajava Guava. In R.J. Garner and S.A. Chaudri. The Propagation of Tropical Fruit Tree. CAB International, New York.
Casanova, L., R. Casanova, A. Moret, \& M. Agusti. 2009. The Application of Gibberellic Acid Increased Berry Size of 'Emperatriz' Seedless Grape. Span.J.Agric. Res. 7 (4): 919-927

Cirami, R.M., E.J. Cameron, \& P.R. Hedberg. 1992. Special Culture Methods for Tablegrapes on Coombe BG and PR Dry. (Eds) Viticulture vol.2 Practices. Pp 279-327

Da Silva. 2013. Gibberellic Acid Fermented Extract Obtained By Solid-State Fermentation Using Citric Pulp by Fusarium moniliforme: Influence on Lavandula angustifolia Mill., Cultivated In Vitro. Pak.J.Bot.45 (6): 2057-2064.

Dagara, A., A. Wekstera, H. Fiedmana, \& S. Luriea. 2012. Gibberellic Acid $\left(\mathrm{GA}_{3}\right)$ Application at The End of Pit Ripening: Effect on Ripening and Storage of Two Harvest of 'September Snow' Peach. Scientia Hort. 140: 125-130.

Handrian, R.G., Meiriani, \& Haryati. 2013. Peningkatan kadar vitamin $\mathrm{C}$ buah tomat (Lycopersicum esculentum MILL.) dataran rendah dengan pemberian hormon $\mathrm{GA}_{3}$. Jurnal Online Agroekoteknologi, 2 (1): 333 339.

Mosure, J. $2004 . \quad$ Vitamin C. http://www.ohioline.osu.edu. Diakses tanggal 23 Desember 2013.

Pardal, S. J. 2001. Pembentukan Buah Partenokarpi melalui Rekayasa Genetika. Buletin Agrobio 4(2):4549.

Parimin. 2005. Jambu Biji. Budidaya dan Ragam Pemanfaatannya. Penebar Swadaya. Jakarta. 131 hal.

Pemerintah Provinsi Bali. 2013. Peraturan Pemerintah Propinsi Bali Nomor 3 Tahun 2013 tentang Perlindungan Buah Lokal. 
NI NYOMAN ARI MAYADEWI DAN I MADE SUKEWIJAYA. Perbaikan Kualitas Buah Jambu...

Prabawati, E.K. 2005. Potensi Sari Buah Jambu Biji untuk Meningkatkan Trombosit darah. Skripsi. Departemen Ilmu dan Teknologi Pangan, Fakultas Teknik Pertanian IPB Bogor. 51 hal.

Sari, Y. 2010. Pengaruh Konsentrasi $\mathrm{GA}_{3}$ dan Pemupukan Npk terhadap Keragaan Tanaman Cabai Sebagai Tanaman Hias Pot. Skripsi. Institut Pertanian Bogor. Bogor.

Sastry, K. K. S. \& Muir R. M. 1963. Gibberellin: Effect on Diffusible Auxin in Fruit Development. Science 140: 494-495.

Sobir dan M. Amalya. 2011. Bertanam 20 Buah Koleksi Eksklusif. Penebar Swadaya. Jakarta. 204 hal.

Susilo, J. 2013. Sukses Bertanam Jambu Biji dan Jambu Air. Penerbit Pustaka Baru Press. Yogyakarta. 180 hal.

Wei, X., S.R. Stykes, \& P.R. Clingeleffer. 2002. An Investigation To Estimate Genetic Parameters In CSIRO'S Table Grape Breeding Program. 2. Quality Characteristic. Euphytica 128: 343-351. 